\title{
Portion Size: Latest Developments and Interventions
}

\author{
Ingrid Steenhuis $^{1} \cdot$ Maartje Poelman $^{2}$
}

Published online: 6 March 2017

(C) The Author(s) 2017. This article is published with open access at Springerlink.com

\begin{abstract}
Purpose of Review The aim of this review is to provide an overview of (1) underlying mechanisms of the effect of portion size on energy intake, (2) external factors explaining the portion size effect and (3) interventions and measurements aimed at food portion size.

Recent Findings Previous studies have shown that portion sizes have increased in recent decades. Many experimental studies have been conducted to unravel the mechanisms underlying the portion-size effect on food intake (e.g. the appropriateness mechanism, the 'unit bias' mechanism, the 'previous experience/expectation' mechanism, the 'visual cue' mechanism and the 'bite size' mechanism). In addition, external factors have been found to drive food portion selection and consumption (e.g. value for money, mindless eating, levels of awareness, estimation bias. Research on several interventions (ranging from 'providing information' to 'eliminating choice') have been conducted, but remain scarce, especially intervention studies in which portion size is a key focus in weight loss. Moreover, only three new instruments with respect to portion control behavior have been developed.

Summary There is considerable evidence for the portion-size effect on energy intake. However, the work on interventions
\end{abstract}

This article is part of the Topical Collection on Etiology of Obesity

Ingrid Steenhuis

Ingrid.steenhuis@vu.nl

1 Department of Health Sciences, Faculty of Earth \& Life Sciences, Vrije Universiteit Amsterdam, Amsterdam Public Health Research Institute, Amsterdam, The Netherlands

2 Department of Human Geography and Spatial Planning, Utrecht University, Heidelberglaan 2, PO Box 80115, 3508 TC Utrecht, The Netherlands targeting portion size and measurements for portion control behavior are limited. Moreover, from the literature it is not yet clear what type of interventions work best, for whom and in what context.

Keywords Portion size $\cdot$ Portion-size interventions · Energy intake $\cdot$ Portion-size effect

\section{Introduction}

In the past few decades, the prevalence of obesity and overweight in adults has increased, more than doubling since the 1980s [1]. Overweight and obesity are related to various health problems such as diabetes mellitus type 2, cardiovascular disease and several types of cancer [2]. Moreover, overweight and obesity are associated with certain psychosocial problems, such as depression and anxiety disorders [3]. In tandem with the increased prevalence of overweight and obesity, an increase in food portion sizes has also been observed [4]. These growing food portion sizes might well be one of the factors contributing to the increased prevalence of overweight and obesity in adults.

In recent years, several studies have been conducted to shed light on the mechanisms behind the portion-size effect. Moreover, increasing attention has been paid to interventions aimed at portion size. This paper presents an overview of recent developments. Notwithstanding the fact that the portionsize effect is also present in children, this paper focuses on the adult population, as the effects are largest in adults $[5 \bullet, 6 \bullet]$.

\section{Trends in Food Portion Sizes}

Very few studies have been conducted into trends in food portion sizes, with most carried out in or before 2009 . 
Studies on developments in food portion sizes have been conducted in the USA [4, 7-10], the UK [11, 12], Denmark [13] and the Netherlands [14]. All of these studies showed that portion sizes of numerous energy-dense foods have increased in the past decades, also highlighting the introduction of 'super-sized' portions. Examining changes in food portions between 2000 and 2009, Young and Nestle [10] showed that this trend has continued into the present century, noting the introduction of many new larger sized portions [10]. With respect to home-cooked meals, Wansink and Payne [15] have demonstrated that portion sizes, as stated in a popular cookbook, have increased over the past 70 years [15], while Eidner et al. [16] found the same trend over the past 100 years in the case of a Danish cookbook [16]. Given this apparent continuing and constant change in portion sizes and noticeable international differences [17], it is important to follow up these studies and continue the monitoring of food portion sizes globally.

\section{Effects of Portion Size on Energy Intake}

Numerous studies have demonstrated that people's energy intake increases when they are offered larger portions. In a meta-analytic review, Zlatevska et al. [6•] showed that doubling a food portion leads, on average, to an increase in energy consumption of $35 \%$ [6•]. In their Cochrane review, Hollands et al. [5•] also found a consistent effect of portion size on energy intake. They estimated that the energy intake from food and non-alcoholic beverages attributable to differences in product sizes was between 215 and $279 \mathrm{kcal} /$ day [5•]. Benton [18] emphasized the fact that we need more studies of real-life situations to establish the true effect of portion size on energy intake in daily life [18]. Such a study was conducted by French et al. [19], who demonstrated that exposure to a high-energy lunch over a period of 6 months led to significant increases in energy intake and weight gain in a real-life work setting [19].

\section{Underlying Mechanisms of the Portion-Size Effect}

Many experimental studies have been conducted over the past decade to unravel the mechanisms underlying the portion-size effect on food intake. Dual process theory may be important to the understanding of these mechanisms, distinguishing between a system of deliberate, conscious reasoning and a more automatic and fast system of associative reasoning [20]. Some studies have attempted to unravel the deliberate processes that steer portion-size selection using a cognitive approach to explain the portion-size effect whereas other studies have attempted to unravel the non-deliberate processes using an automatic approach in explaining the portion-size effect [21, 22•]. Below, we briefly summarize the key mechanisms that are frequently highlighted when explaining the portion-size effect. A more in-depth and comprehensive explanation of the underlying mechanisms of the portion-size effect can be found in recently published papers by Herman et al. [23] and English et al. [22•, 23].

- The appropriateness mechanism. Although the evidence is not conclusive and there have been mixed results over recent years, the most prevalent explanation for the portion-size effect is the concept of 'appropriateness'. According to this perspective, a food portion sets a norm and guides the amount consumed. Consequently, the portion size (rather than hunger or satiety) directs food consumption and steers food intake. Marchiori et al. used the term 'anchoring effect'(aligning it with the appropriateness effect) to explain how portion sizes work as an anchor or reference point [24]. As Herman et al. [23] mention in their review, the 'fractional version' of the appropriateness mechanism should be further explored, as people often do not consume the entire portion, but only a 'fraction' of the portion size served [23]. Questions remain about what fraction of the portion is appropriate, does this differ for different people and how does this amount emerge?

- The 'unit bias' mechanism. This model suggest people see one serving (e.g. one sandwich, one can of food, one biscuit) as appropriate to consume at once, irrespective of its size [25]. Kerameas et al. [26] argued that the term 'segmentation bias' might be more applicable, as they found that people eat less when food is divided into smaller units [26]. Eating a number of smaller units rather than eating one larger unit is perceived by consumers as more impulsive and less appropriate [27].

- The 'previous experiencelexpectation' mechanism. Previous experiences may steer portion-size selection. For example, previous experience of the 'degree of fullness produced by a food' impacts on the portion size selected and consumed at a later point in time [28]. A study by Brunstrom et al. [29] showed that cognitive expectations about satiety and satiation influence the portion size selected [29].

- The 'visual cue' mechanism. The portion-size effect might be partly explained by visual cues, for example dishware size. People may use visual cues to steer their portion-size intake. For example, the degree of 'plate emptiness' may activate meal termination [21]. The Delboeuf illusion is also frequently mentioned in the literature to explain how similar portion sizes of food appear larger served on a small plate than on a large plate, and this steers individuals to judge portions differently [30].

The size of dishware has been studied more intensively in recent years. This is of interest as it has been found 
that people frequently use large-sized dishware at home [31]. However, with respect to plate size, a recent systematic review and meta-analysis showed that there is no consistent effect of plate size on food intake [32]. It has also been found that plate size does not affect people's estimation of the portion size [33]. However, a modelling study showed a positive association between plate size and energy available [34]. Moreover, the rim width of the plate might also influence portion-size selection (the larger the rim width, the less is served) [35]. In buffet experiments, smaller plates did not result in less food being consumed [36, 37]. Libotte et al. [38] demonstrated that participants increased their vegetable serving when using the large-sized plate [38].

- The bite size mechanism. Similarly to the use of laundry powder, toothpaste or spaghetti-where people pour out or use more when the package size is larger [39] —it has been found that people increase their bite size when food portions are larger [21, 40].

\section{External Factors Explaining the Portion-Size Effect}

Additional factors that are not addressed by the portion-size effect - or the way the portion is served - may also impact on the portion size consumed. A wide range of external factors influence food consumption (and surplus portion-size intake), but a few important external factors that are frequently suggested in the literature as affecting the portion size selected and consumed are explained below.

- Value for money. Larger portion sizes can usually be offered at a proportionally low cost, since the cost of the food itself is relatively low compared to other costs such as labour [10]. The concept of 'value for money' has been identified as an important incentive in relation to consumers selecting larger portions [39, 41]. Consumers are likely to pay marginally more for a larger portion when several food portion options are available because they feel they are getting more value for money. Value for money can therefore be seen as a mechanism underlying the consumption of larger portions.

- Mindless eating. In the past decades, many studies have been conducted showing that individuals who engage in mindless eating (eating while distracted and not focused on the food they are consuming) consume larger amounts. Mindless eating impairs an individual's ability to accurately estimate the amount of food they consume and they are hindered from making deliberate decisions on how much they should eat [42]. When eating mindlessly, individuals report lower degrees of fullness and a greater desire to eat compared to those who are not distracted
[43]. Consequently, individuals are at risk of consuming surplus amounts when sufficient food is available [44]. Watching television, playing a computer game, listening to the radio and dining with others are factors that typically lead to mindlessly eating larger amounts than intended [45-48]. A recent review by Robinson et al. indicated that mindless eating is associated with a moderate increase in the immediate intake as well as a larger intake at a later point in time. Moreover, the effect of mindless eating was independent of dietary restraint [32].

- Awareness and estimation bias. People have difficulties in estimating amounts of food [49] and, moreover, are unaware of reference portion sizes [50]. There might also be some individual differences in the capacity to estimate appropriate portion sizes; for example, men tend to have more difficulties with this task [51]. Other studies have suggested that factors such as body mass index [52], the perceived healthiness of the product [53] or the energy density of the product [50] might play a role.

\section{Interventions Aimed at Portion Size}

Although we know increasingly more about the portion-size effect and its working mechanisms, interventions tackling the portion-size effect are still scarce. Nevertheless, some interventions have been developed and tested recently (see Table 1). Interventions can be categorized according to the ladder of interventions of the British Nuffield Council on Bioethics [65], starting with simply providing information and ending with the more rigorous intervention of eliminating choice (i.e. not offering large portion sizes at all, see Fig. 1).

As Table 1 shows, most of the interventions that have been developed and tested are on the lower rungs of the ladder. Some interventions showed promising results, such as using segmentation cues in food packaging [57], forming implementation intentions [60] and the use of other self-regulatory, portion control strategies [31,61•].

Studies with portion size as the key focus in weight loss interventions are still very rare. A study by Poelman et al. [17] showed that a decrease in BMI can be achieved by focusing on different strategies, solely to control food portion sizes. The effects on BMI were mediated through portion control behaviours [61•]. This is in accord with the findings of the SHED-IT trial, where portion size was found to be one of the mediators of the intervention effect on body weight at 6 months, alongside physical activity [66].

More research into interventions aimed at portion size, in which all rungs of the ladder are taken into account, is required. The higher rungs of the ladder might not be reached without government regulation and thus government action 


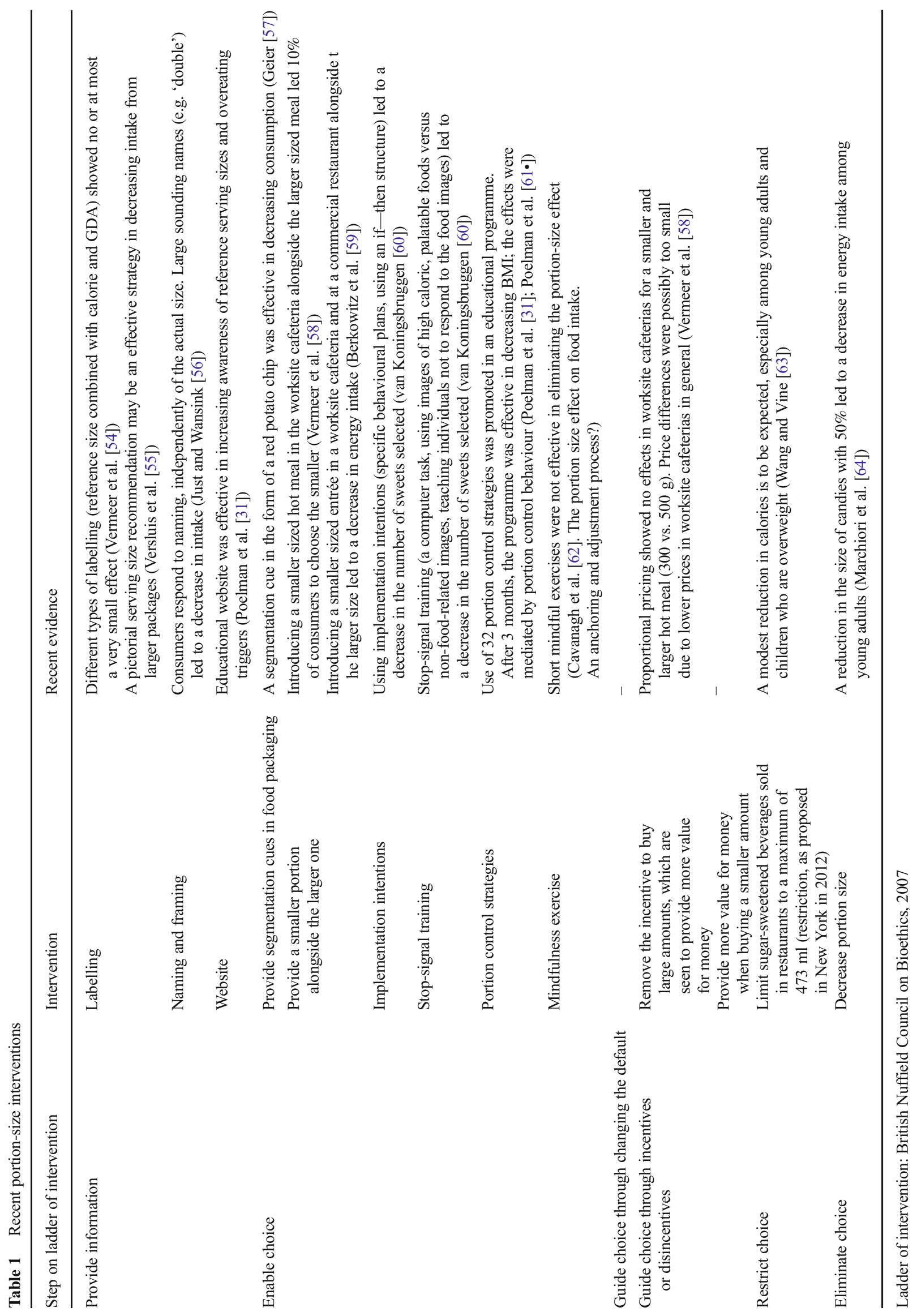


Fig. 1 A ladder of interventions. From Public health: ethical issues, with kind permission from the Nuffield Council on

Bioethics. Accessible at http:// nuffieldbioethics.org/wp-content/ uploads/2014/07/Public-healthethical-issues.pdf, (C) Nuffield Council on Bioethics 2007

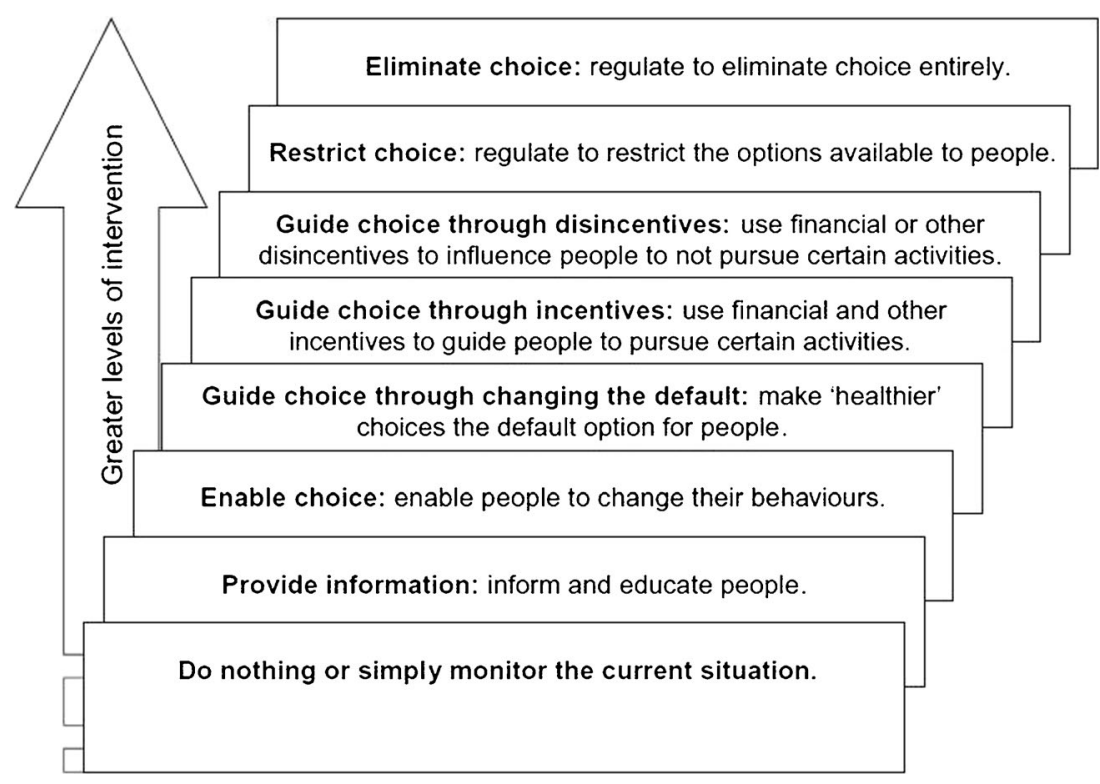

will need to be combined with non-regulatory interventions to ensure use of the entire ladder of interventions aimed at tackling the portion-size effect (see e.g. Marteau et al. [67]). Marteau et al. [67] also noted that public acceptance is of crucial importance if governments and other private parties are to act [67]; however, public acceptance of the government intervening in the food environment is in general rather low. In their study of the public acceptance of policies to reduce the consumption of sugar-sweetened beverages, Gollust et al. [68] found that American consumers appeared to be most in favour of labelling and restricting sales on school property, while the least support was found for taxes and portion-size restrictions. It could well be that public acceptance decreases as interventions climb the ladder of interventions although this might be slightly different in the case of interventions targeted at children [68]. More insight into the public acceptance of policy measures targeted at portion size will help in the development of strategies to enhance acceptance of policies.

In addition to public acceptance, it is also of importance to include intermediaries, such as restaurant owners in the development of strategies to control portion size. For example, Gase et al. [69] studied a voluntary programme in which restaurants offered reduced sized portions. Although they concluded that the programme was feasible, many barriers to offering reduced sized portions were identified by the restaurant owners, such as logistical barriers and concerns about revenue loss. Moreover, healthy eating was mainly seen as the responsibility of the consumer [69].

\section{Measurement Instruments}

With the increasing attention being paid to interventions, the need for measurements of portion control behaviour has emerged. In recent years, three new instruments have been developed (see Table 2). Fast et al. [70] developed a portion control self-efficacy scale, which showed good validity and reliability, with scores on the scales associated with dieting success $[70,31]$. derived 32 portion control strategies from the literature, with the overall Cronbach's $\alpha$ of the scale valued at .82 and showed an association between the use of portion control strategies and reduced BMI [31].

The portion control practices questionnaire developed by Spence et al. [71] consists of three subscales: the measurement strategy (use of guidance, i.e. by means of suggested serving sizes), the eating strategy (practices such as eating slowly) and the purchasing strategies (buying or ordering smaller amounts). Cronbach's $\alpha$ of all subscales was $\geq .78$, and an association was found between the eating strategy

Table 2 Measurement instruments portion control behaviour

Instrument and authors Type of instrument

Portion control self-efficacy 12 -item questionnaire on a 5-point scale, (Fast et al. [70]) measuring self-efficacy toward portion control

Portion control strategies (Poelman et al. 2013)

32-item questionnaire on a 5-point scale, measuring strategies to control the amount eaten. Strategies concern: purchase behaviour; meal and package sizes; stockpiling; food exposure and unplanned eating; mindless eating; and dining out, all-you-can-eat and take away food

Portion control practices (Spence et al. [71])

15-item questionnaire on a 4-point scale, measuring the use of portion control practices. 3 sub-scales include measurement strategy scale, eating strategy scale and purchasing strategy scale 
scale and reduced BMI, whereas both the eating and purchasing strategies were negatively associated with pizza consumption [71]. These studies by Poelman et al. (2013) and Spence et al. [71] suggest that portion control strategies may improve food intake and support weight control. However, more research is needed into the validity of portion control behaviour scales and the associations with food intake and BMI $[31,71]$.

\section{Conclusion and Further Directions}

Clearly, there is considerable evidence for the portion-size effect. However, there is still a lot of work to be done with respect to interventions targeting portion size. Although we conclude that a promising start has been made in relation to interventions targeting portion size, it is not yet clear what type of interventions work best, for whom and in what context [72]. Specific attention should be directed to the public acceptance of portion-size interventions and in particular portionsize policies. Based on the very limited number of studies thus far, targeting portion size seems a promising strategy for weight loss interventions but this should be explored further. Interventions should be developed and tested in real-life settings [18]. It is of importance to include the whole spectrum of potential interventions, from providing information to eliminating choices, from voluntary changes to regulatory interventions [54]. Moreover, valid measurements should be developed to evaluate the effects of interventions. While a few portion control scales have been developed, more research is needed into their validity and the associations with food intake as well as BMI.

Acknowledgements We would like to thank Frédérique Rongen (MSc) for her assistance in preparing the manuscript.

\section{Compliance with Ethical Standards}

Conflict of Interest Ingrid Steenhuis has received compensation from Brickhouse Academy for providing training to dieticians and other paramedics about behaviour change and the obesogenic environment (including portion size) and royalties from Scriptum Publishers and SWP Publishing for writing two books - one on SMARTsize and one on relapse.

Maartje Poelman has received royalties from Scriptum Publishers for writing a book on SMARTsize.

Human and Animal Rights and Informed Consent This article does not contain any studies with human or animal subjects performed by any of the authors.

Open Access This article is distributed under the terms of the Creative Commons Attribution 4.0 International License (http:// creativecommons.org/licenses/by/4.0/), which permits unrestricted use, distribution, and reproduction in any medium, provided you give appropriate credit to the original author(s) and the source, provide a link to the Creative Commons license, and indicate if changes were made.

\section{References}

Papers of particular interest, published recently, have been highlighted as

- Of importance

1. WHO. Factsheet overweight and obesity. 2016. Retrieved from $\mathrm{http} / / / w w w . w h o . i n t / m e d i a c e n t r e / f a c t s h e e t s / \mathrm{fs} 311 / \mathrm{en} /$

2. Hruby A, Manson JAE, Qi L, Malik VS, Rimm EB, Sun Q, et al. Determinants and consequences of obesity. American Journal of Public Health. 2016;106:1656-62.

3. Jansen A, Havermans R, Nederkoorn C, Roefs A. Jolly fat or sad fat? Subtyping non-eating disordered overweight and obesity along an affect dimension. Appetite. 2008;51(3):635-40.

4. Young LR, Nestle M. The contribution of expanding portion sizes to the US obesity epidemic. Am J Public Health. 2002;92(2):246-9.

5. Hollands GJ, Shemilt I, Marteau TM, Jebb SA, Lewis HB, Wei Y, et al. Portion, package or tableware size for changing selection and consumption of food, alcohol and tobacco. Cochrane Database Syst Rev. 2015;9(9), CD011045. A Cochrane review about, among other factors, the portion-size effect on energy intake. Estimation that the energy intake from food and nonalcoholic beverages attributable to differences in product sizes was between $215-279 \mathrm{kcal} / \mathrm{day}$.

6. Zlatevska N, Dubelaar C, Holden SS. Sizing up the effect of portion size on consumption: a meta-analytic review. J Mark. 2014;78(3): 140-54. A review about the portion size effect on energy intake finding that doubling a food portion leads, on average, to an increase in energy consumption of $35 \%$.

7. Nielsen SJ, Popkin BM. Patterns and trends in food portion sizes, 1977-1998. JAMA. 2015;289(4):450-3.

8. Smiciklas-Wright H, Mitchell DC, Mickle SJ, Goldman JD, Cook A. Foods commonly eaten in the United States, 1989-1991 and 1994-1996: are portion sizes changing? J Am Diet Assoc. 2003;103(1):41-7.

9. Young LR, Nestle M. Portion sizes and obesity: responses of fastfood companies. J Public Health Policy. 2007;28(2):238-48.

10. Young LR, Nestle M. Reducing portion sizes to prevent obesity: a call to action. American Journal of Preventive Medicine. 2012;43: $565-8$.

11. Wrieden W, Gregor A, Barton K. Have food portion sizes increased in the UK over the last 20 years? Proc Nutr Soc. 2008; 67:(OCE), E211.

12. Benson C. Increasing portion size in Britain. Soc Biol Hum Aff. 2009;74:4-20.

13. Matthiessen J, Fagt S, Biltoft-Jensen A, Beck AM, Ovesen L. Size makes a difference. Public Health Nutr. 2003;6(1):65-72.

14. Steenhuis IHM, Leeuwis FH, Vermeer WM. Small, medium, large or supersize: trends in food portion sizes in The Netherlands. Public Health Nutr. 2010;13(6):852-7.

15. Wansink B, Payne CR. The joy of cooking too much: 70 years of calorie increases in classic recipes. Annals of Internal Medicine. 2009; 150:291.

16. Eidner MB, Lund A-SQ, Harboe BS, Clemmensen IH. Calories and portion sizes in recipes throughout 100 years: an overlooked factor in the development of overweight and obesity? Scand J Public Health. 2013;41(8):839-45.

17. Poelman MP, Eyles H, Dunford E, Schermel A, L'Abbe MR, Neal $B$, et al. Package size and manufacturer-recommended serving size of sweet beverages: a cross-sectional study across four high-income countries. Public Health Nutr. 2015;19(6):1-9.

18. Benton D. Portion size: what we know and what we need to know. Crit Rev Food Sci Nutr. 2015;55(7):988-1004. 
19. French SA, Mitchell NR, Wolfson J, Harnack LJ, Jeffery RW, Gerlach AF, et al. Portion size effects on weight gain in a free living setting. Obesity (Silver Spring). 2014;22(6):1400-5.

20. Kahneman D. A perspective in judgment and choice: mapping bounded rationality. Am Psychol. 2003;58(9):697-720.

21. Burger KS, Fisher JO, Johnson SL. Mechanisms behind the portion size effect: visibility and bite size. Obesity (Silver Spring). 2011;19(3):546-51.

22. English L, Lasschuijt M, Keller KL. Mechanisms of the portion size effect. What is known and where do we go from here? Appetite. 2015;88:39-49. A paper explaining the portion-size effect. Mechanisms that are explored are visual cues, labeling, size of packaging and plate size.

23. Peter Herman C, Polivy J, Pliner P, Vartanian LR. Mechanisms underlying the portion-size effect. Physiol Behav. 2015;144:129-36.

24. Marchiori D, Papies EK, Klein O. The portion size effect on food intake. An anchoring and adjustment process? Appetite. 2014;81: $108-15$.

25. Geier AB, Rozin P, Doros G. Unit bias: a new heuristic that helps explain the effect of portion size on food intake. Psychol Sci. 2006;17(6):521-5.

26. Kerameas K, Vartanian LR, Herman CP, Polivy J. The effect of portion size and unit size on food intake : unit bias or segmentation effect ? Health Psychol. 2015;34(6):670-6.

27. van Kleef E, Kavvouris C, van Trijp HCM. The unit size effect of indulgent food: how eating smaller sized items signals impulsivity and makes consumers eat less. Psychol Health. 2014;446(April 2014):1-23.

28. Hardman CA, McCrickerd K, Brunstrom JM. Children's familiarity with snack foods changes expectations about fullness. Am J Clin Nutr. 2011;94(5):1196-201.

29. Brunstrom JM, Burn JF, Sell NR, Collingwood JM, Rogers PJ, Wilkinson LL, et al. Episodic memory and appetite regulation in humans. PLoS One. 2012;7(12):e50707.

30. Van Ittersum K, Wansink B. Plate size and color suggestibility: the Delboeuf illusion's bias on serving and eating behavior. J Consum Res. 2012;39(2):215-28.

31. Poelman MP, De Vet E, Velema E, Seidell JC, Steenhuis IHM. Behavioural strategies to control the amount of food selected and consumed. Appetite. 2014;72:156-65.

32. Robinson E, Nolan S, Tudur-Smith C, Boyland EJ, Harrold JA, Hardman CA, et al. Will smaller plates lead to smaller waists? A systematic review and meta-analysis of the effect that experimental manipulation of dishware size has on energy consumption. Obes Rev. 2014;15(10):812-21.

33. Penaforte FRO, Japur CC, Diez-Garcia RW, Hernandez JC, PalmmaLinares I, Chiarello PG. Plate size does not affect perception of food portion size. J Hum Nutr Diet. 2014;27(SUPPL2):214-9.

34. Pratt IS, Croager EJ, Rosenberg M. The mathematical relationship between dishware size and portion size. Appetite. 2012;58(1):299302.

35. McClain AD, van den Bos W, Matheson D, Desai M, McClure SM, Robinson TN, et al. Visual illusions and plate design: the effects of plate rim widths and rim coloring on perceived food portion size. Int J Obes (Lond). 2013;38(August):1-6.

36. Rolls BJ, Roe LS, Halverson KH, Meengs JS. Using a smaller plate did not reduce energy intake at meals. Appetite. 2007;49(3):652-60.

37. Yip W, Wiessing KR, Budgett S, Poppitt SD. Using a smaller dining plate does not suppress food intake from a buffet lunch meal in overweight, unrestrained women. Appetite. 2013;69:102-7.

38. Libotte E, Siegrist M, Bucher T. The influence of plate size on meal composition. Literature review and experiment. Appetite. 2014;82: 91-6.

39. Wansink B. Can package size accelerate usage volume? J Mark. 1996;60(July):1-13.
40. Almiron-Roig E, Tsiountsioura M, Lewis HB, Wu J, Solis-Trapala I, Jebb SA. Large portion sizes increase bite size and eating rate in overweight women. Physiol Behav. 2015;139:297-302.

41. Steenhuis IH, Vermeer WM. Portion size: review and framework for interventions. Int J Behav Nutr Phys Act. 2009;6(August):58.

42. Moray J, Fu A, Brill K, Mayoral MS. Viewing television while eating impairs the ability to accurately estimate total amount of food consumed. Bariatr Nurs Surg Patient Care. 2007;2(1):71-6.

43. Brunstrom J, Mitchell G. Effects of distraction on the development of satiety. Br J Nutr. 2006;96:761-9.

44. Stroebele N, De Castro JM. Effect of ambience on food intake and food choice. Nutrition. 2004;20(9):821-38.

45. Bellisle F, Dalix AM, Slama G. Non food-related environmental stimuli induce increased meal intake in healthy women: Comparison of television viewing versus listening to a recorded story in laboratory settings. Appetite. 2004;43(2):175-80.

46. Boulos R, Vikre EK, Oppenheimer S, Chang H, Kanarek RB, Obesi TV. How television is influencing the obesity epidemic. Physiol Behav. 2012;107:146-53.

47. de Castro J, Brewer E. The amount eaten in meals by humans is a power function of the number of people present. Physiol Behav. 1992;51:121-5.

48. Oldham-Cooper RE, Hardman CA, Nicoll CE, Rogers PJ, Brunstrom JM. Playing a computer game during lunch affects fullness, memory for lunch, and later snack intake. Am J Clin Nutr. 2011;93(2):308-13.

49. Nørnberg T, Houlby L, Jørgensen L, He C, Pérez-Cueto F. Do we know how much we put on the plate? Assessment of the accuracy of self-estimated versus weighed vegetables and whole grain portions using an Intelligent Buffet at the FoodScape Lab. Appetite. 2014;81:162-7.

50. Almiron-Roig E, Solis-Trapala I, Dodd J, Jebb SA. Estimating food portions. Influence of unit number, meal type and energy density. Appetite. 2013;71:95-103.

51. Lewis H, Forwood S, Ahern A, Verlaers K, Robinson E, Higgs S, et al. Personal and social norms for food portion sizes in lean and obese adults. Int J Obes. 2015;39(8):1319-24.

52. Lewis HB, Ahern AL, Solis-Trapala I, Walker CG, Reimann F, Gribble FM, et al. Effect of reducing portion size at a compulsory meal on later energy intake, gut hormones, and appetite in overweight adults. Obesity. 2015;23(7):1362-70.

53. Faulkner GP, Pourshahidi LK, Wallace JMW, Kerr MA, McCaffrey TA, Livingstone MBE. Perceived "healthiness" of foods can influence consumers' estimations of energy density and appropriate portion size. Int J Obes (Lond). 2014;38(1):106-12.

54. Vermeer W, Steenhuis I, Poelman M. Small, medium, large or supersize? The development and evaluation of interventions targeted at portion size. Int J Obes. 2014;38:13-8.

55. Versluis I, Papies EK, Marchiori D. Preventing the pack size effect: exploring the effectiveness of pictorial and non-pictorial serving size recommendations. Appetite. 2015;87:116-26.

56. Just DR, Wansink B. One man's tall is another man's small: how the framing of portion size influences food choice. Health Econ. 2014;23:776-91.

57. Geier A, Wansink B, Rozin P. Red potato chips: segmentation cues can substantially decrease food intake. Health Psychol. 2012;31(3): 398-401.

58. Vermeer WM, Steenhuis IHM, Leeuwis FH, Heymans MW, Seidell JC. Small portion sizes in worksite cafeterias: do they help consumers to reduce their food intake? Int J Obes. 2011;35:1200-7.

59. Berkowitz S, Marquart L, Mykerezi E, Degeneffe D, Reicks M. Reduced-portion entrées in a worksite and restaurant setting: impact on food consumption and waste. 2016;19:3048-54.

60. Van Koningsbruggen GM, Veling H, Stroebe W, Aarts H. Comparing two psychological interventions in reducing impulsive 
processes of eating behaviour: effects on self-selected portion size. Br J Health Psychol. 2014;19(4):767-82.

61. Poelman MP, de Vet E, Velema E, de Boer MR, Seidell JC, Steenhuis IHM. PortionControl@HOME: results of a randomized controlled trial evaluating the effect of a multi-component portion size intervention on portion control behavior and body mass index. Ann Behav Med [Internet]. 2014; Available from: http://www.ncbi. nlm.nih.gov/pubmed/25142041. Randomized controlled trial into portion control strategies in a weight loss program, showing that a significant decrease in BMI was achieved by focusing on portion control behaviours.

62. Cavanagh K, Vartanian LR, Herman CP, Polivy J. The effect of portion size on food intake is robust to brief education and mindfulness excercies. J Health Psychol. 2014;19:730-9.

63. Wang YC, Vine SM. Caloric effect of a 16-ounce (473-mL) portion-size cap on sugar-sweetened beverages in restaurants. AJCN. 2013;98:430-5.

64. Marchiori D, Waroquier L, Klein O. Smaller food item sizes of snack foods influence reduced portions and caloric intake in young adults. J Am Diet Assoc. 2011;111:727-31.

65. Nuffield Council on Bioethics. Public health: ethical issues. London, UK. 2007. Accessible at http://nuffieldbioethics.org/wpcontent/uploads/2014/07/Public-health-ethical-issues.pdf.
66. Young MD, Lubans DR, Collins CE, Callister R, Plotnikoff RC, Morgan PJ. Behavioral mediators of weight loss in the shed-it community randomized controlled trial for overweight and obese men. Ann Behav Med. 2015;49(2):286-92.

67. Marteau TM, Hollands GJ, Shemilt I, Jebb SA. Downsizing: policy options to reduce portion sizes to help tackle obesity. BMJ. 2015;5863(December):h5863.

68. Gollust SE, Barry CL, Niederdeppe J. Americans' opinions about policies to reduce consumption of sugar-sweetened beverages. Prev Med (Baltim). 2014;63:52-7.

69. Gase L, Dunning L, Kuo T, Simon P, Fielding JE. Restaurant owners' perspectives on a voluntary program to recognize restaurants for offering reduced-size portions, Los Angeles County, 2012. Prev Chronic Dis. 2014;11(7), E44.

70. Fast LC, Harman JJ, Maertens JA, Burnette JL, Dreith F. Creating a measure of portion control self-efficacy. Eat Behav. 2015;16: 23-30.

71. Spence M, Lähteenmäki L, Stefan V, Livingstone MBE, Gibney ER, Dean M. Quantifying consumer portion control practices. A cross-sectional study. Appetite. 2015;92:240-6.

72. Livingstone MBE, Pourshahidi LK. Portion size and obesity. Adv Nutr. 2014;5(6):829-34. 